\title{
Comparative Study Age at Time Operation between Younger and Older than 18 Months for Development Dysplasia of the Hip in Children
}

\author{
Nguyen Ngoc Hung, Hoang Hai Duc, Nguyen Do Ngoc Hien \\ Vietnam National Hospital of Pediatrics, Hanoi, Vietnam \\ Email: ngocyenhung@gmail.com
}

How to cite this paper: Hung, N.N., Duc, H.H. and Hien, N.D.N. (2018) Comparative Study Age at Time Operation between Younger and Older than 18 Months for Development Dysplasia of the Hip in Children. Open Access Library Journal, 5: e4378.

https://doi.org/10.4236/oalib.1104378

Received: January 26, 2018

Accepted: February 25, 2018

Published: February 28, 2018

Copyright $\odot 2018$ by authors and Open Access Library Inc.

This work is licensed under the Creative Commons Attribution International License (CC BY 4.0).

http://creativecommons.org/licenses/by/4.0/

\begin{abstract}
Background: The Innominate osteotomy as an integral component of combined open reduction for the treatment of dysplasia developed of the hip in children. Materials and Methods: Between 2011 and 2015, 198 hips of 176 patients with developmental dislocation of the hip underwent 0 operation. The patients were divided into two Variant based on the age at the time of open reduction: 12 months - less than 18 months (Variant 1) and upper 18 36 months (Variant 2). There were 120 hips in V 1 and 69 hips in V 2. Preoperative Patients didn't use skin or skeletal traction, or femoral osteotomies. All patients were Open reduction and iliac osteotomy according to Zigzag morphology combined Fibular Allograft. Dislocations were graded according to Tönnis system. The acetabular index was measured common procedure: Clinical evaluation of modified McKay criteria, and Roentgenographic evaluation of Severin. Results: There were $134(76.1 \%)$ of the patients were girls and 42 (23.9\%) were boys. Twenty two (12.5\%) patients were affected bilaterally. The right hip was involved in 31 (17.6\%), and the left hip in 123 cases (69.9\%). Tönnis grade: Tönnis 3 in 46 (23.3\%), Tönnis. 4 in 152 (76.7\%). The patient was performed at a mean age of 21.5 months (12 to 36 ) and the mean age at latest follow-up was 72.1 months (58 to 115), and the mean time follow-up was 41 months (32 to 53 months).Overall favorable result 188 hips (94.9\%) and unfavorable result 10 hips (5.1\%). Roentgenogrphic results were Excellent 79.8\%, Good 15.2\%, Fair 3.5\%, Poor 1.5\%. There were Redislocation 14 (7.1\%) and Avascular necrosis 47 (23.7\%). Conclusion: This operation was of good safety and efficacy. Fibular allograft was strength and graft was not resorption, more stable and structurally sound interposition material which could be contoured to the shape of the osteotomy site. The Zizag octeotomy acetabuloplasty the same shape of the acetabulum by hinging the horizontal branch of the triradiate cartilage following an incomplete osteotomy. At latest results, both Variant were none different.
\end{abstract}




\section{Subject Areas}

Orthopedics

\section{Keywords}

Hip Dysplasia, Congenital Dislocation of the Hip, Innominate Osteotomy, Development Dysplasia of the Hip, Allograft

\section{Introduction}

Developmental Dysplasia of the hip (DDH) includes femoral head subluxation or Dislocation and/or acetabular Dysplasia. The goal of treatment for Developmental Dysplasia of the Hip (DDH) is to reduce the method by a closed or open method and maintain this decline through childhood and adolescence. If the concentric stability is maintained, the stabilizer will have potential to recover and continue to grow and develop normally [1] [2]. When the interaction between the forces of natural remodeling of the hips and primary treatment failures, surplus continuity resulting in acetabular dysplasia. Dysplasia threatens long-term function by increasing the chance of early degenerative disease [3] [4].

Early diagnosis and early intervention are the main causes of DDH. When the diagnosis is made early in most cases, treatment of ligaments or braces will be satisfactory. Unfortunately, there are still a few patients who are not sick early. Diagnosis or early treatment, leads to surgical treatment. These children should be treated surgically. In general, the choice of treatment for DDH is usually age related and needs to be adjusted to fit the specific conditions. Surgical options include reduction of open and capsulorhaphy alone or in combination with acetabular procedure. However, there is still debate as to when or why these procedures are required [5].

The age of the patient is one of the important factors in determining the treatment in the developmental disturbance of the hip.

Bone removal is recommended if the patient is 18 months or older [6]. Salter and other researchers report excellent radiographic findings for patients aged 18 months to 4 years when Salter's alveolar innominate osteotomy was performed with open cuts [6] [7]. They also recommend open surgery with necrosis simultaneously, as better results will be achieved with a one-stage operation than the procedure being held.

Treatment of children over 12 months of age disordered in the groin more challenging. In addition, older children should have scars of acetabulum, such as Salter or Pemberton methods to cover the femoral head [8] [9]. The Congenital hip replacement therapy in the elderly began to become difficult because of the appropriate shortening of the soft tissues of the extra-articular, acetabular dysplasia, capsular constriction, increased fernoralanteversion, and fixed inversion 
of the limbs [10] [11].

Open reduction (OR) of the hip and Salter's osteotomy have become a popular treatment for late onset of DDH in a single attempt [12] [13]. These failures are still a challenging clinical problem as the revision surgery has been associated with high rate of stiffness, residual dysplasia and avascular necrosis (AVN) [14] [15].

The choice of the type of pelvic osteotomy depends on careful pre-operative assessment of the severity of the acetabular dysplasia and also the age of the patient at the time of treatment [16].

The revascularization capacity the acetabulum decreases steadily in the first 6 or 7 years of life, so if the acetabulum contains the femoral head poorly an attempt should be made to improve the acetabular cover [17].

The authors have over the years, are not satisfied that iliac crest autograft as the interposition material for the osteotomy is structurally sound and full stability. Problems such as extrusion, rotation and absorption, leading to loss of acetabularcorrection, were often noted in cases previously treated at our National Hospital for Pediatrics. Autograft concern is further supported by authors who suggest the routine use internal fixation, especially in older children.

Bone allografts have commonly been used in orthopaedic practice, and in articular, in pediatric orthopaedic surgery with good safety and efficacy [18].

The purpose of this paper is to review our experience with the management of Congenital Dislocation of the hip in children in whom treatment was not begun until between the ages of one and three years with open reduction and modified innominate osteotomy combined fibular allograft. Based on this experience, a safe and effective approach to this problem will be presented.

\section{Materials and Methods}

Between 2011 and 2015, 198 hips of 176 patients with DDH underwent open reduction. $134(76.1 \%)$ of the patients were girls and $42(23.9 \%)$ were boys. Twenty two (12.5\%) patients were affected bilaterally. $154(87.5 \%)$ patients were affected unilaterally. The right hip was involved in thirty-one (17.6\%) and the left hip in one handrad-twenty tree (69.9\%) cases (Table 1 ). Tönnis system type 3 in 46 hips (23.3\%) and Type 4 in 152 hips (76.7\%) hips.

Patients hadteratologic dislocations, neuromuscular disorders and connective tissue, and patients with a history of a previous open hip procedure at another hospital were excluded from the study. Patients Tönnis grades I and II were excluded. Only patients presenting with grades III and IV were included in this study. This study was retrospective evaluating results and complications following ZOFA.

The operations were performed by a single surgeon (Author) and the evaluation by two independent orthopedic surgeons, who were not members of the department.

Informed consent was obtained from all participants. The study had the 
Table 1. Data of the patient.

\begin{tabular}{|c|c|c|c|c|c|c|c|c|c|c|c|}
\hline & \multirow{2}{*}{$\begin{array}{l}\text { Number } \\
\text { Patients }\end{array}$} & \multicolumn{2}{|c|}{ Sex } & \multicolumn{3}{|c|}{ Side } & \multicolumn{2}{|c|}{ Tönnis grade } & \multirow{2}{*}{$\begin{array}{c}\text { Age at } \\
\text { Operation } \\
\text { (months) }\end{array}$} & \multirow{2}{*}{$\begin{array}{c}\text { Age La. } \\
\text { F-U } \\
\text { (months) }\end{array}$} & \multirow{2}{*}{$\begin{array}{c}\text { Time } \\
\text { F-U } \\
\text { (months) }\end{array}$} \\
\hline & & Boy & Girl & Left & Right & Bilateral & $\begin{array}{l}\text { Tön. } 3 \\
\text { (Hips) }\end{array}$ & $\begin{array}{l}\text { Tön. } 4 \\
\text { (Hips) }\end{array}$ & & & \\
\hline Variant 1 & 115 & 25 & 90 & 80 & $\begin{array}{l}21 \\
129 \mathrm{Hi}\end{array}$ & 14 & 28 & 101 & $\begin{array}{c}14.4 \\
(12-18)\end{array}$ & $\begin{array}{c}69.7 \\
(58-102)\end{array}$ & $\begin{array}{c}41.8 \\
(31-52)\end{array}$ \\
\hline \multirow[t]{2}{*}{ Variant 2} & 61 & 17 & 44 & 43 & $\begin{array}{l}10 \\
69 \mathrm{Hi}\end{array}$ & 8 & 18 & 51 & $\begin{array}{c}29.6 \\
(19-36)\end{array}$ & $\begin{array}{c}74.4 \\
(72-115)\end{array}$ & $\begin{array}{c}40.2 \\
(32-53)\end{array}$ \\
\hline & 176 & 42 & 134 & 123 & $\begin{array}{l}31 \\
198 \mathrm{Hi}\end{array}$ & 22 & 46 & 152 & $\begin{array}{c}22 \\
(12-36)\end{array}$ & $\begin{array}{c}72.1 \\
(58-115)\end{array}$ & $\begin{array}{c}41 \\
(32-53)\end{array}$ \\
\hline
\end{tabular}

Age La.F-U: Age at latest Follow-up; Time F-U: Time Follow-up; ). Age La.F-U: Age at latest Follow-up; Time F-U: Long time Follow-up.

approval of the Ethical Review Committee of our Institute and was carried out in accordance with the tenets of the Declaration of Helsinki.

The patients were divided into two Variants based on the age at the time of OR: 12 months - less than 18 months (Variant $1-\mathrm{V}$ 1) and upper $18-36$ months (Variant $2-\mathrm{V} 2$ ). There were 120 hips in V 1 and 69 hips in V 2. None had preoperative skin or skeletal traction, nor derotationalvarus or valgus osteotomies. The patient was performed at aaverage age of 22 months (12 to 36) and the average at latest follow-up was 72.1 months (58 to 115), and the average time follow-up was 41 months (32 to 53 months).

Dislocations of the hip according to use Tönnis system [4]. The acetabular index was measured as common procedure to evaluate the correction of the acetabulardysplasia and the subsequent maintenance thereof [19].

We elected not use the central-edge angle of Weiberg ( $\mathrm{CE}$ angle), as the femoral heads in the majority of hips were partially ossified.

\subsection{Surgical Technique}

Total hips, the position of maximum stability was assessed at the time of OR. The hips which required flexion with abduction for stability and/or had an acetabular angle above $30^{\circ}$ on the pre-operative radiograph, were judged to require an innominate osteotomy. If under general anestheria could not abductor hipabove $60^{\circ}$ should adduction of mucusletenotomy. The Zadeh's Test of stability [20] was used after open reduction, which was the main indicator for the need of the pelvic osteotomies. Expose inner table of the ilium only, did not expose outer table of the ilium. A drill used to sketchiliac osteotomy. The first line, transversal line at just above anterior inferior iliac spine $5 \mathrm{~mm}$; the second line, go down and internal oblique to create angle $90^{\circ}$ or $135^{\circ}$ with the first line (create $90^{\circ}$ angle with $\mathrm{AI}<45^{\circ}$ and $135^{\circ}$ with $\mathrm{AI}>135^{\circ}-\propto$ angle) distance $5-7 \mathrm{~mm}$ length; the thirst line, to go internal obliquely to create angle $90^{\circ}-135^{\circ}$ too, with the second line (create $90^{\circ}$ angle with $\mathrm{AI}<45^{\circ}$ and $135^{\circ}$ with $\mathrm{AI}>135^{\circ}-\beta$ angle) (Figure 1) distance $8-10 \mathrm{~mm}$ length and to the transversal level of the first line; the fourth line, connective thirst line and go down, distance $10 \mathrm{~mm}$ length; the 
fifth line, perpendicular to the fourth line, to go internal transversal line, distance 6 - $8 \mathrm{~mm}$ length. After outlining the iliac osteotomy is created by multiple drill-holes, a small sharp osteotome is used to complete the cuts by connecting those drill-holes (Figure 1).

Next, using small curette to remove cancellous in both side on top and bottom segment of ilium to create a slot receiving fibula allograft. The Fibular Allograft is placed between the two side of the ilium and maintains the displacement (Figure 2), so that Fibular grafting lateral displacement $2 \mathrm{~mm}$ is needed, and fibular allograft is compressed between both side on top and bottom segment of ilium.

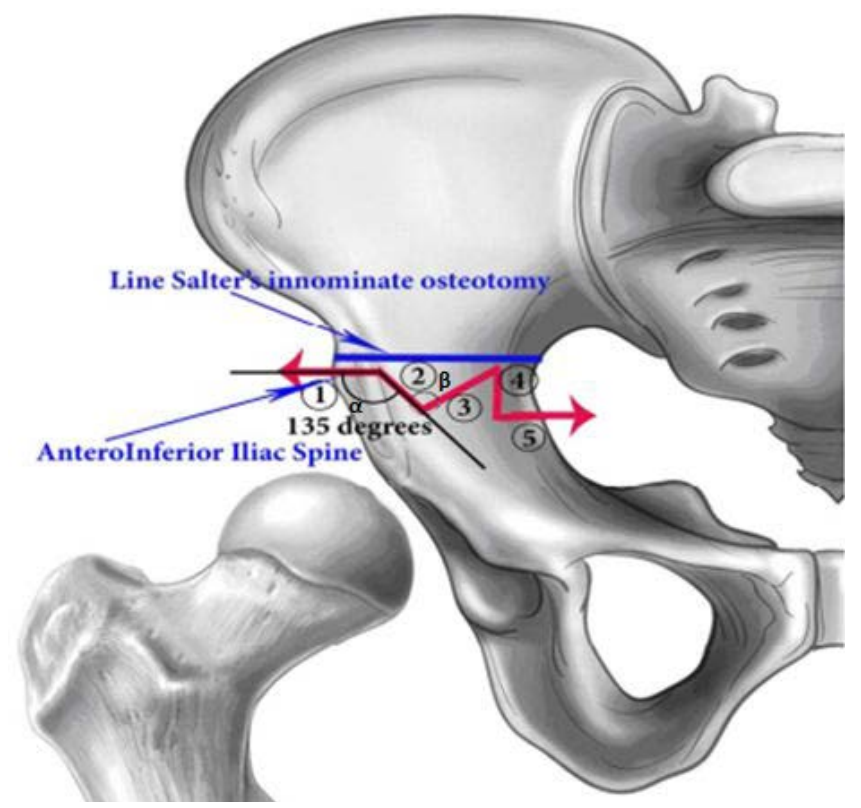

Figure 1. Lines osteotomy of Ilium. Angle $\beta$ and $\propto$ are $135^{\circ}$.

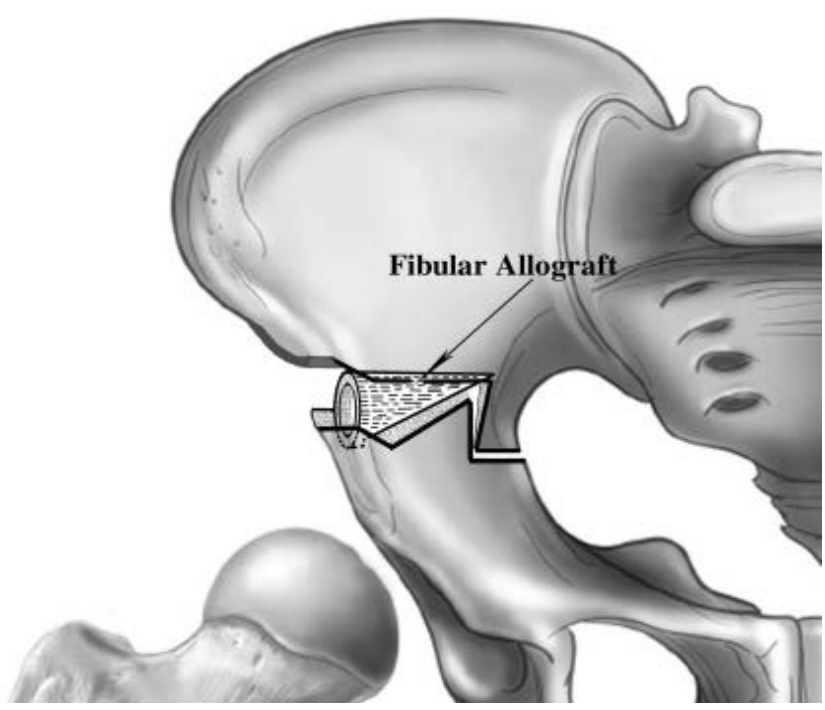

Figure 2. The fibular allograft is placed between the two fragments of Ilium. 
To measure the distance to the underside of the pelvic segment from 11 to 13 $\mathrm{mm}$, the equilibrium equal distance from anterior superior iliac spine to anterior inferior iliac spine and the lower front hip was measured according to Salter's technique [4].

The osteotomy should be very stable when the two segments are engaged.

The distal segment of the ilium occurs to turn through the pubic symphysis, as in salter grafts, and is pulled in exactly the same way, so that anterior and lateralacetabular coverage occurs simultaneously, as as described by Salter and Dubos [4] [6]. The Osteotomy is held open with a wedge of bone graft, whose base is length from the anterior superior to anterior inferior iliac spine, which reliably improves anterior and lateral coverage 25 degrees and 15 degrees respectively [4].

The rotation of the distal segment occurs through the pubic symphysis, as in the Salter osteotomy, and is pulled in exactly the same way, so that frontal and outer acetabular coverage occurs simultaneously, as described by Salter and Dubos [4] [6].

The fibula allografts that were used in this treatment protocol were imported from bone banks that adhere to the standards of Asia Association Surgery Tissue Bank. These graphs are of a sort (dry freeze) processing that has been proven to be safe [21].

A bilateral hip spica cast with the hips in human position was applied at surgery. Hip spica was maintained for 3 months and then a full-time abduction brace was used for 3 months. Afterwards, the brace was worn at night for an additional 3 months for a total brace time of 6 months.

\subsection{Evaluating Result}

The patients were scheduled to return to the outpatient clinic at three months intervals during the first time postoperatively 3 months, 6 months, 1 year, and 2 years after surgery and then at yearly intervals.

Patients were evaluated clinically for each visit such as the range of motion of affected hips, the quality of walking, the Trendelenburgtest, and the presence of any pain.

Radiation of each hip was performed to assess quality of decline, AI, and presence or absence of AVN. The preoperative radiographic image of each patient was evaluated to determine the AI and the station.

Leg length variation can be measured by a physician during a physical examination and through X-rays. Usually, the doctor measures the hip level when the child is standing barefoot

Assessment of AVN of the femoral head was classified according to Kalamchi and MacEwen's classification [22]: Grade 1: Changes affecting the ossific nucleus; Grade 2: Lateral physeal damage; Grade 3: Central physeal damage; Grade 4: Total damage to the head and physis.

Details of radiological classified according to the Severin [23] was used for the 
radiologic assessment of postoperative results: Gade 1: Normal; Grade 2: Moderate deformity of femoral head or neck or acetabulum; Grade 3: Dysplastic no subluxed; Grade 4: Subluxed; Grade 5: Head articulating with secondary acetabulum in upper of the original acetabulum; Grade 6: Dislocated; Grade 7: Arthritic.

Barrett's modification of McKay's criteria [24] was classified for the clinical assessment of postoperative results: Excelent result: Stable, painless hip, no limp, negative Trendelenburg sign, full range of motion; Good result: Stable, painless hip, slight limp, slight degree in range of motion; Fair result: Stable, painless hip, limp, positive Trendelenburg sign, and limited range of motion, or a combination of these; Poor result: Unstable or painful hip, or both, positive Trendelenburg sign.

\subsection{Statistical Analysis}

The data were analysed with Epi Info 6.04 software public domain statistical software for epidemiology, developed by Centers for Disease Control and Prevention (CDC) in Atlanta, Georgia, USA, http://wwwn.cdc.gov/epiinfo/html/prevVersion.htm. We performed the $\chi^{2}$ test for percentage and the t-student test for mean comparison between the preoperative and postoperative groups. P-values less than 0.05 was regarded as statistically significant. All values were provided as mean values along with the appropriate standard deviation.

\section{Results}

There were 176 patients (189 hips) who had intraoperative instability and received an OR and ZOFA. Gender: boy are 42 (23.9\%), girl are $134(76.1 \%)$. Number hip: 129 hips (65.2\%) in V1, 69 hips (34.8\%) in V2, total: 198 hips. Side: bilateral were $22(12.5 \%)$, left were $123(69.9 \%)$, right were 31 (17.6\%). Tönnis grade: Tönnis 3 in 46 (23.3\%) hips, Tönnis. 4 in 152 (76.7\%) hips.

Number patient: 176; Sex: Boy are 42 (23.9\%), Girl are 134 (76.1\%); Number hip: 129 hips (65.2\% ) in V1, 69 hips (34.8\%) in V2, total: 198 hips; Side: Bilateral are $22(12.5 \%)$, Left are $123(69.9 \%)$, Right are 31 (17.6\%); Tönnis grade: Tönnis 3 in 46 (23.3\%) hips, Tönnis. 4 in 152 (76.7\%) hips. Age at time Operation: 22 months (12 - 36 months). Age at latest Follow-up: 72.1 months (58 - 115). Duration Follow-up: 41 months (32 - 53).

Variant 1/Variant 2 show: Acetabular Index: Preopration 46.98/50; PostOperation 24 months: $20.5^{\circ} / 19.8^{\circ}$; At latest $18.5^{\circ} / 17.8^{\circ}$; Improvement Pre-Immediate Operation of AI: $23.26^{\circ}$ (49.5\%)/27.7 ${ }^{\circ}$ (55.1\%), Pre-At latest: $28.8^{\circ}(61.3 \%) / 32.5^{\circ}$ (64.6\%). Overall: Pre-Operation AI $=50.07^{\circ} \mathrm{SD}=4.973$ Immediatelly Operatiom $\mathrm{AI}=22.96^{\circ} \mathrm{SD}=2.252$, and Latest Follow-up AI: $17.9^{\circ} \mathrm{SD}=1.56 . \mathrm{Im}$ provement of Preoperation and Latest follow-up $32.17^{\circ}$ (64.25\%). The Hips with AI Above 45 degrees both variant (younger and older than 18 months) Pre-Operative immediately and Postoperative 24 moths - Latest were not statis- 
tically significant $(\mathrm{P}$ valuate $>0.05)$ (Table 2$)$.

Overall: Pre-Operation $\mathrm{AI}=46.5^{\circ} \mathrm{SD}=4.567$ Immediately Operatiom $\mathrm{AI}=$ $25.35^{\circ} \mathrm{SD}=2.398$, and Latest Follow-up AI: $18.7^{\circ} \mathrm{SD}=1.645$. Improvement of Preoperation and Latest follow-up 27.8 (59.5\%). Comparative AI Pre-Postoperative immediately, Postoperative 24 months - Latest of Patients abover and belower $45^{\circ}$ were not statistically significant ( $\mathrm{P}$ valuate $>0.05$ ) (Table 3 ).

Table 2. The hip with acetabular index abover 45 degrees.

\begin{tabular}{|c|c|c|c|c|c|c|c|c|}
\hline & \multirow[b]{2}{*}{ No. Hip } & \multicolumn{7}{|c|}{ Acetabular Index } \\
\hline & & $\begin{array}{c}\text { Pre-Op } \\
\left({ }^{\circ}\right)\end{array}$ & $\begin{array}{c}\text { Imm.Op } \\
\left({ }^{\circ}\right)\end{array}$ & $\begin{array}{l}\text { PostOpe. } \\
3 \text { mo }\left({ }^{\circ}\right)\end{array}$ & $\begin{array}{c}\text { PostOpe. } \\
6 \text { mo }\left({ }^{\circ}\right)\end{array}$ & $\begin{array}{l}\text { PostOpe. } \\
12 \mathrm{mo}\left({ }^{\circ}\right)\end{array}$ & $\begin{array}{l}\text { PostOpe. } \\
24 \text { mo }\left({ }^{\circ}\right)\end{array}$ & $\begin{array}{c}\text { At latest } \\
\left({ }^{\circ}\right)\end{array}$ \\
\hline \multirow{6}{*}{$\mathrm{V} 1$} & 17 & $46.98^{\circ}$ & $23.72^{\circ}$ & 22.86 & 21.76 & 20.88 & 20.5 & 19.8 \\
\hline & SD & 4.21 & 2.58 & 2.11 & 2.28 & 1.79 & 1.34 & 1.60 \\
\hline & Range & $45.2-61.2$ & $20.9-26.8$ & $19.2-25.4$ & $17.8-25.2$ & $16.6-22.5$ & $16.1-22.3$ & $14.4-21.6$ \\
\hline & $\mathrm{P}$ valuate & \multicolumn{2}{|c|}{$<0.05$} & & & & \multicolumn{2}{|c|}{0.06486} \\
\hline & Impro. & \multicolumn{2}{|c|}{$23.26^{\circ}(49.5 \%)$} & & & & \multicolumn{2}{|c|}{$27.18^{\circ}(57.9 \%)$} \\
\hline & 31 & $50.3^{\circ}$ & $22.6^{\circ}$ & 22.2 & 21.6 & 20.3 & 20.1 & 19.5 \\
\hline \multirow[t]{4}{*}{ V 2} & $\mathrm{SD}$ & 3.16 & 2.62 & 2.44 & 2.12 & 1.82 & $\begin{array}{l}1.46 \\
1.42 \\
1.46\end{array}$ & $\begin{array}{l}1.86 \\
1.60\end{array}$ \\
\hline & Range & $45.2-66.1$ & $20.4-26.2$ & $18.9-25.1$ & $17.7-24.8$ & $16.5-22.1$ & $16.2-22.3$ & $14.8-21.2$ \\
\hline & $\mathrm{P}$ valuate & \multicolumn{2}{|c|}{$<0.05$} & & & & \multicolumn{2}{|c|}{0.071390} \\
\hline & Impro. & \multicolumn{2}{|c|}{$27.7^{\circ}(55.1 \%)$} & & & & \multicolumn{2}{|c|}{$31.2^{\circ}(62.0 \%)$} \\
\hline $\mathrm{P}$ va & $e$ (Impro.) & \multicolumn{2}{|c|}{0.7628} & & & & & 0.6968002 \\
\hline
\end{tabular}

Pre-Op: Pre-Operation; Imm.Op: Operation Immediately; PostOpe.: Post-Operation; mo: month; Impro: Improvement.

Table 3. Change Acetabular index according to age at time operation and AI angles Abover/Belower than 45 degrees.

\begin{tabular}{|c|c|c|c|c|c|c|c|c|}
\hline & \multirow[b]{2}{*}{ No. Hip } & \multicolumn{7}{|c|}{ Acetabular Index } \\
\hline & & $\begin{array}{l}\text { Pre-Op. } \\
\text { (SD) }\end{array}$ & $\begin{array}{l}\text { Imme-Op } \\
\text { (SD) }\end{array}$ & $\begin{array}{c}\text { Post-Op } \\
3 \text { moths (SD) }\end{array}$ & $\begin{array}{c}\text { Post-Op } \\
6 \text { months (SD) }\end{array}$ & $\begin{array}{c}\text { Post-Op } \\
12 \text { months (SD) }\end{array}$ & $\begin{array}{c}\text { Post-Op } \\
24 \text { months (SD) }\end{array}$ & $\begin{array}{c}\text { Latest } \\
\text { Follow-up (SD) }\end{array}$ \\
\hline \multirow{5}{*}{$\mathrm{AI}<45^{\circ}$} & 150 & $42.93^{\circ}$ & $27.74^{\circ}$ & 25.56 & 22.91 & 21.706 & $20.18^{\circ}$ & $19.95^{\circ}$ \\
\hline & SD & 4.404 & 2.545 & 2.070 & 2.280 & 2.014 & 1.662 & 1.753 \\
\hline & Range & $31.2^{\circ}-44.9^{\circ}$ & $26.1^{\circ}-28.5^{\circ}$ & $23.8-26.2$ & $22.4-25.9$ & $22.2-24.6$ & $19.2-23.8$ & $19.2-20.4$ \\
\hline & P. valuate & \multicolumn{2}{|c|}{$<0.05$} & & & & \multicolumn{2}{|c|}{0.128529} \\
\hline & Impro & \multicolumn{2}{|c|}{$15.2^{\circ}(35.4 \%)$} & & & & $22.8^{\circ}(48.5 \%)$ & $23.0^{\circ}(53.6 \%)$ \\
\hline \multirow{4}{*}{$\mathrm{AI}>45^{\circ}$} & 48 & $50.07^{\circ}$ & $22.96^{\circ}$ & 22.53 & 21.68 & 20.59 & $20.15^{\circ}$ & $19.75^{\circ}$ \\
\hline & $\mathrm{SD}$ & 4.973 & 2.252 & 2.275 & 2.00 & 1.805 & 1.450 & 1.315 \\
\hline & Range & $45.2-66.1$ & $20.4-26.8$ & $18.9-25.4$ & $17.7-25.2$ & $16.5-22.5$ & $16.1^{\circ}-22.3^{\circ}$ & $14.4^{\circ}-21.6^{\circ}$ \\
\hline & Impro. & \multicolumn{2}{|c|}{$27.1^{\circ}(53.5 \%)$} & & & & $30.6^{\circ}(60.4 \%)$ & $32.2^{\circ}(64.3 \%)$ \\
\hline \multirow{5}{*}{ Overall } & 198 & $46.5^{\circ}$ & $25.35^{\circ}$ & & & & 20.1 & 19.9 \\
\hline & $\mathrm{SD}$ & 4.567 & 2.398 & & & & 1.432 & 1.649 \\
\hline & Range & $31.2^{\circ}-66.1^{\circ}$ & $26.1^{\circ}-26.8^{\circ}$ & & & & $16.1-23.8$ & $14.4-21.6$ \\
\hline & P. valuate & \multicolumn{2}{|c|}{$<0.05$} & & & & \multicolumn{2}{|c|}{0.10966} \\
\hline & Impro. & \multicolumn{2}{|c|}{$21.7^{\circ}(46.1 \%)$} & & & & \multicolumn{2}{|c|}{$27.8^{\circ}(59.5 \%)$} \\
\hline
\end{tabular}

Pre-Op: Pre-Operation; Imm.Op:Immediate Operation; PostOpe.: Post-Operation. Impro: Improvement. 
Variant 1/Variant 2: Adductor tenotomyin 112 (86.8\%)/69 (100\%) P. valuate: 0.001611; Cutting Ligament teres 102 (79.1\%)/66 (95.7\%) P. valuate: 0.001929; Cutting Limbus 113 (87.6\%)/69 (100\%) P. valuate 0.00278; Tenotomy Psoat tendon 129 (100\%)/69 (100\%): Removed Puvinar 129 (100\%)/69 (100); Removed Transverse Ligament 115 (89.1\%)/65 (84.2\%) P. valuate 0.304256; Capsulorraphy $112(86.8 \%) / 69$ (100\%) P. valuate 0.001611; Kirchner Wire: 129 (100\%)/69 (100\%) (Table 4).

The Compared some surgical techniques of OR were in V1 and V2 such as Adductor tenotomy, Ligament Teres, Limbus, and Capsulorraphy were Statistical significance $(\mathrm{P}$ valuate $<0.05)$; Transverse Ligament was not statistically significant $(\mathrm{P}$ valuate $>0.05)$.

\section{Illustration}

1) A girl, age at operation was 20 months. Dislocation Type IV. She were operated with ZOFA with angle $\propto$ and $\beta$ are $135^{\circ}$. A bilateral hip spica cast with the hips in human position was applied at surgery. Hip spica was maintained for 3 months and then a full-time abduction brace was used for 3 months. Afterwards, the brace was worn at night for an additional $3-4$ months for a total brace time of 6 - 7 months. Abe at Follow-up are 56 months (Postoperative 36 moths), AI are $17.53^{\circ}$, Surgical result are excellent (Figures $3(\mathrm{a})-(\mathrm{c})$ ).

2) A boy, agirl, age at operation was 28 months. Dislocation of left hip, Tönnis grade 4 Preoperative AI $41.2^{\circ}$. He were operated OR combined ZOFA with angle $\beta$ and $\propto$ are $90^{\circ}$. Post Operative 16 weeks, he had subluxation, AI was $22.8^{\circ}$. Patient did anapathology shown bone interface between bone graft and host bone, have new bone cell (Figures 4(a)-(c)).

\section{Discussion}

\subsection{Pelvic Osteotomies}

There are many types of pelvic osteotomies to treat the dysplastic hips. To determine which bone resorption surgery is most appropriate, we should consider the concentric reducibility of femoral head, the age of the patient, and the

Table 4. Datails of OR combined ZOFA.

\begin{tabular}{|c|c|c|c|c|c|c|c|c|c|}
\hline & \multirow[b]{2}{*}{$\begin{array}{l}\text { No. } \\
\text { Hip }\end{array}$} & \multicolumn{8}{|c|}{ Surgical procedures } \\
\hline & & $\begin{array}{c}\text { Adductor } \\
\text { Tenotomy } \\
(\%)\end{array}$ & $\begin{array}{c}\text { Ligament } \\
\text { Teres } \\
(\%)\end{array}$ & $\begin{array}{c}\text { Limbus } \\
(\%)\end{array}$ & $\begin{array}{c}\text { Psoat } \\
\text { Tendon } \\
(\%)\end{array}$ & $\begin{array}{c}\text { Puvinar } \\
(\%)\end{array}$ & $\begin{array}{c}\text { Transverse } \\
\text { Ligament } \\
\text { (\%) }\end{array}$ & $\begin{array}{c}\text { Capsulorraphy } \\
(\%)\end{array}$ & $\begin{array}{c}\text { Kirchner } \\
\text { Wire }^{*} \\
(\%)\end{array}$ \\
\hline Variant 1 & 129 & $\begin{array}{c}112 \\
(86.8)\end{array}$ & $\begin{array}{c}102 \\
(79.1)\end{array}$ & $\begin{array}{c}113 \\
(87.6)\end{array}$ & $\begin{array}{c}129 \\
(100)\end{array}$ & $\begin{array}{c}129 \\
(100)\end{array}$ & $\begin{array}{c}115 \\
(89.1)\end{array}$ & $\begin{array}{c}112 \\
(86.8)\end{array}$ & $\begin{array}{c}129 \\
(100)\end{array}$ \\
\hline Variant 2 & 69 & $\begin{array}{c}69 \\
(100)\end{array}$ & $\begin{array}{c}66 \\
(95.7)\end{array}$ & $\begin{array}{c}69 \\
(100)\end{array}$ & $\begin{array}{c}69 \\
(100)\end{array}$ & $\begin{array}{c}69 \\
(100)\end{array}$ & $\begin{array}{c}65 \\
(84.2)\end{array}$ & $\begin{array}{c}69 \\
(100)\end{array}$ & $\begin{array}{c}69 \\
(100)\end{array}$ \\
\hline $\mathrm{P}$ valuate & & 0.001611 & 0.001929 & 0.00278 & & & 0.304256 & 0.001611 & \\
\hline
\end{tabular}

Kirschner wire*: Kirschner wire was passed through the greater trochanter and into the ilium. 


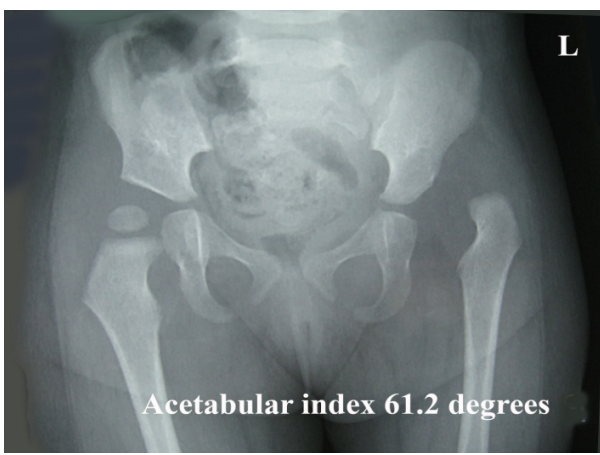

(a)

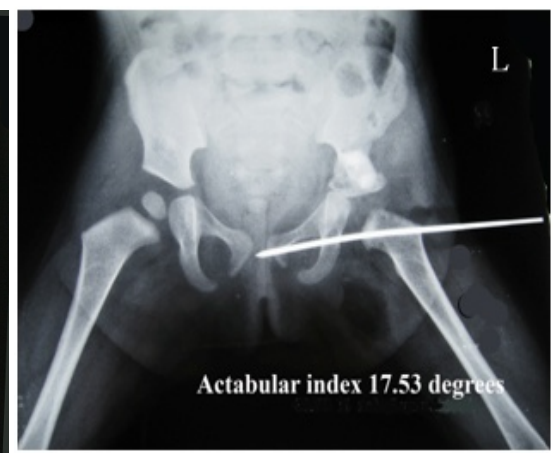

(b)

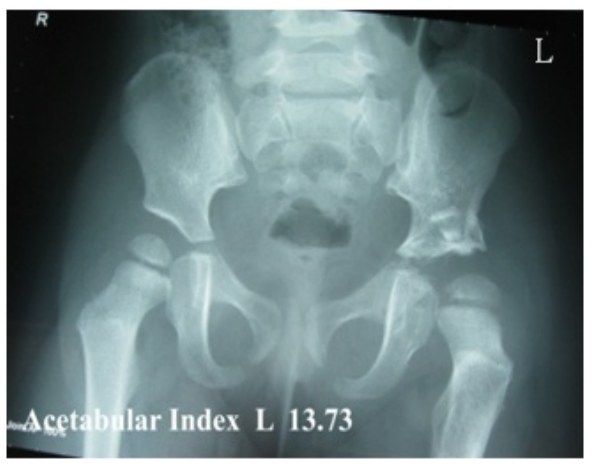

(c)

Figure 3. (a) PreOperation AI $61.2^{\circ}$, (b) Operate Immediately AI $17.53^{\circ}$, (c) Postoperative 36 months - AI $13.73^{\circ}$.

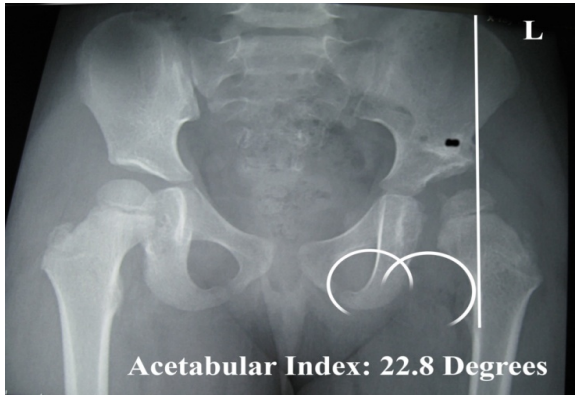

(a)

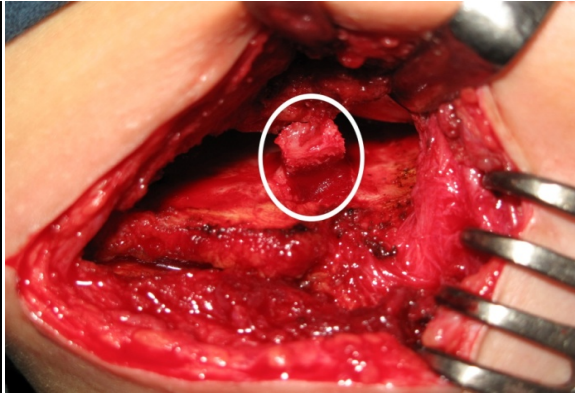

(b)

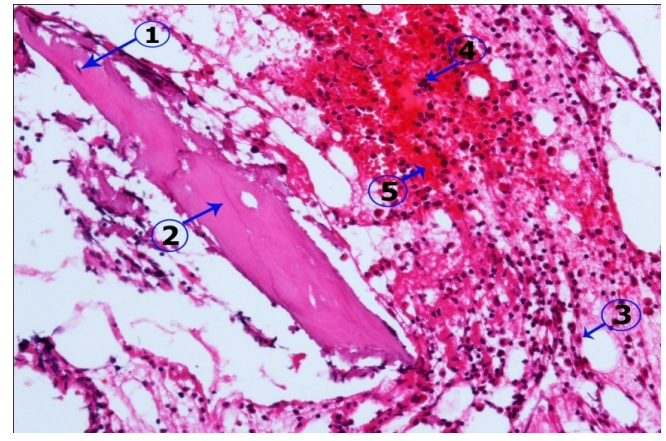

(c)

Figure 4. (a)-(c): Bone interface between bone graft and host bone, have shown new bone cell (Biopsy of material obtained 16 weeks post-operation). 1) Osteocyte in lacuna; 2) Compact bone; 3) Eosinophils; 4) Hematopoisis; 5) Erythrosys. 
condition of the triradiate cartilage.

For the patients with late diagnosed late $\mathrm{DDH}$, reconstructive osteotomy for dysplastic acetabulum is indicated only when the femoral head can be concentrically reduced. Salter innominate osteotomy and Pemberton osteotomy are the most commonly used procedures for children younger than 7 years old [25].

Salter osteotomy and Pemberton acetabuloplasty are common procedures for the lack of acetabulum in the developmental disorder of DDH hip (Figure 5).

Salter osteotomy redirects the entire acetabulum following a complete trans-iliac osteotomy, while Pemberton acetabuloplastychange the type of the hinging the horizontal branch of the triradiate cartilage following an iliac cutting is not complete. The goal of these two procedures is to improve the coverage of the femoral head for acetabular dysplasia.

The pericapsularacetabuloplasty described by Pemberton in 1965, is a method of pelvic osteotomy. Through incomplete cut in the ilium, this procedure can redirect the acetabulum to achieve correction of acetabular dysplasia. Early research by Pemberton showed a positive rate of achievement in children under 7 years of age. Later, some authors have achieved a good results in older children when they applied one stage Pemberton acetabuloplasty and femoral shortening as a one-stage operation [25]. In addition, to obtain correction of acetabular dysplasia that is greater potentially greater than that achieved with the Salter osteotomy, the Pemberton osteotomy can be performed without the use of internal fixation. The object of the surgery is to improve anterolateral coverage of the

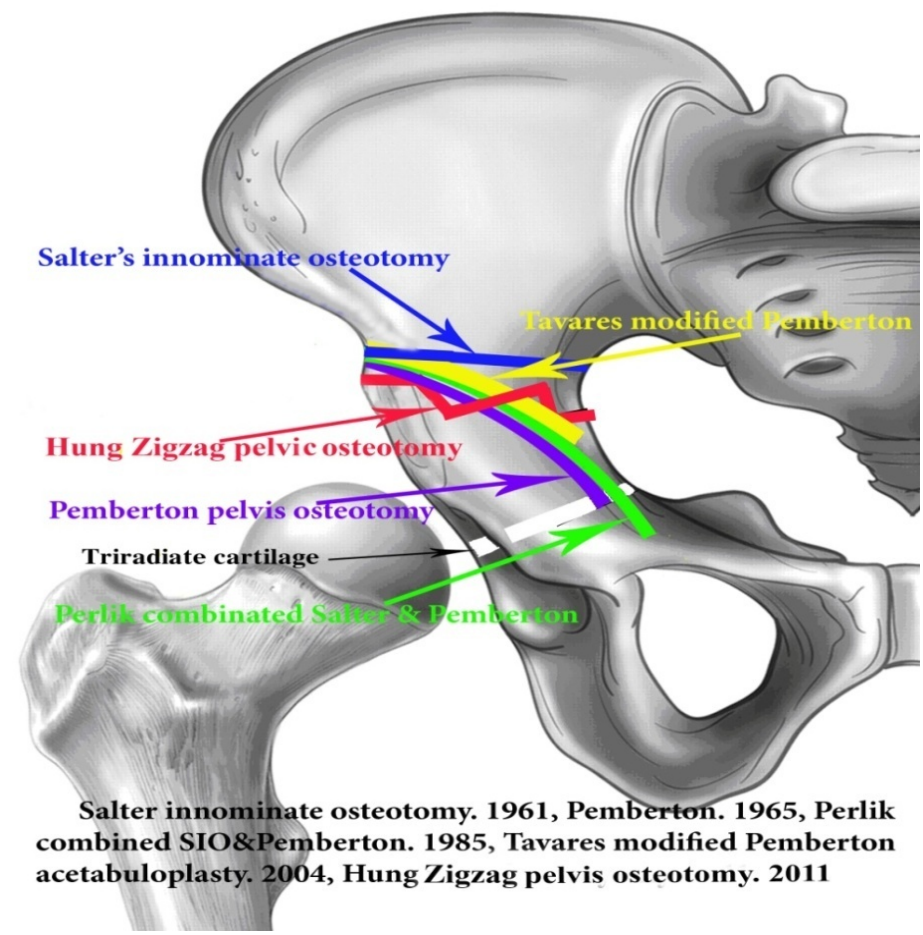

Figure 5. Some Iliac Osteotomy, to begin at above anterior inferior iliac spine such as Pemberton PA. 1965 [25], Salter RB.1961 [26], Tavares JO [27], Perlik PC et al. [28], Hung NN. 2011 [29]. 
femoral head. Full control and a stable hip allow for weight gain and osseous remodelling of the dysplastic acetabulum.

Salter. 1961 described the innominate osteotomy for stabilizing the reduced hip by redirection of the acetabulum as a unit. The procedure was accomplished by a transverse osteotomy of the ilium perpendicular to the iliac axis from just above the anterior inferior iliac spine to the sciatic notch. It was designed to preserve the acetabular shape while correcting the abnormal anterolateral facing of the acetabulum in DDH. The public symphysis served as a rotating hinge and the acetabulum can be redirected to cover the anterolateral deviciency in a concentrically reduced hip after the osteotomy.

Cervical dissection serves as a rotating hinge and the acetabulum can be diverted to cover the anterolateral deficiency in a joint that decreases concentrically after the osteotomy [25].

Salter and Dubos showed good or good results in patients treated from 18 months to 4 years and without failureconsideration within 15 years of follow-up of 140 patients.

In the 410 age group, the results achieved excellent or good results or only reached $56.7 \%$ [6]. Thus, the Salter osteotomy do not use the method in older children.

This procedure may be the most widespread pelvic osteotomy in DDH treatment. In compared the Pemberton osteotomy, the Salter's procedure seems relatively simple. However, proper implementation strategies are needed to resolve the logisof it is not easy. The most common error that leads to a catastrophic outcome is failure to achieve a concentric reduction of the hip joint before innominate osteotomy.

We performing iliac osteotomy in $\mathrm{DDH}$ with Zizag osteotomy. The procedure was accomplished by a transverse osteotomy of the ilium perpendicular to the iliac axis from just above the anterior inferior iliac spine to the $5 \mathrm{~mm}$ ( 1 line), line $2(5 \mathrm{~mm})$, they create angle $90^{\circ}$ with $\mathrm{AI}<45^{\circ}$ and $135^{\circ}$ with $\mathrm{AI}>45^{\circ}$ to the sciatic notch. Line 2 and 3 to create angle the same line 1 and 2 too (Figure 1 ). Our line have bar osseous is created line 4 and 5. The bar osseous bar to prevent move of postero-internal distal ilia. The Zizagocteotomyacetabuloplastyhave hinging the horizontal branch of the triradiate cartilage following an incomplete osteotomy and the aim of this procedures are to improve the anterolateral coverage of the femoral head. Immediately operate (Figure 2), AI improvement $27.1^{\circ}(53.5 \%)$ with Iliac osteotomy have angle $\beta$ and $\propto$ are $135^{\circ}$ for $\mathrm{AI}>45^{\circ}$, it was compared with Iliac osteotomy have angle $\beta$ and $\propto$ are $90^{\circ}$ for $\mathrm{AI}<45^{\circ}$ (Table 4, P valuate 0.02384, Statistical significance.)

There are two bar osseous and two slots in proximal and distal segment of the ilium, this stability is evident intra-operatively by the graft not being able to be translated or rotated or sliped. This transplant stability specifically removes the need for conventional internal fixation of bone-cutting surgery. Extrusion or transfer of graft were not encountered in our series. 
In the document, the rate of graft displacement ranges between $0 \%$ and $17 \%$, the rate of graft displacement ranges between $0 \%$ and $17 \%$ [24] [30] [31] [32]. In zigzag osteotomy combined fibular allograt, the rate of graft displacement was $0 \%$ in this study. This post-operative result of graft may be the result of the care taken to check the stability of the graft with this technique (Figure 2). The post-operation, all of the fibulat allografts were completely incorporated average 14 weeks (range, 12 weeks - 17 weeks).

Acetabular Index have changed and improvement clearly was to $15.2^{\circ}$ (improvement $35.4 \%$ ) of $\mathrm{V} 1$ and $27.1^{\circ}$ (improvement 53.5\%) of $\mathrm{V} 2$ in immediate operation (Table 3), so Capsulorrhaphy easily and reduce tighten the posterior capsule will be prevent posterior subluxation of the head especially if a iliac osteotomy has been performed simultaneously.

Harris et al. 1975 [33]. Seventy-two patients with eighty-five hips were studied. The children were above one year old on admission and abover the years at the time of review.

The development of the acetabulum assessed by radiography by measuring the angle of the acetabulum. Angles less than 21 degrees were considered normal, and more than 21 degrees as indicated by some failure of growth.

Satisfactory acetabular development occurred at $80 \%$ (24degrees or less) and unsatisfactory at $20 \%$ (above 24 degrees angle).

Satisfactory acetabular development occurred in 80 per cent (angles 24 degrees or below), and was unsatisfactory in 20 per cent (angles above 24 degrees).

Severin. 1941 [23] suggested that 21 degrees at the age of ten or more ys the critical angle of normality. If the angle was less than 21 degrees the acetabulum was regarded as normal; if more than 21 degrees some failure of development of varying degree was conceded and these were classified as good (22 - 24 degrees), fair (25 - 27 degrees) and poor if the angle exceeded 27 degrees. The post-operative 24 months with $\mathrm{AI}$ are $20.1^{\circ}$ and latest result $19.9^{\circ}$ in this study.

The Salter osteotomy is suitable for an acetabulum with a short iliac part and an acetabular angle of up to $35^{\circ}$, whereas the Pemberton acetabuloplasty is suitable for an acetabulum with a long iliac part and an acetabular angle of up to $50^{\circ}$ [30] [34] or $45^{\circ}$ [35]. The SIO initially described both tables of ilium being exposed, increasing the amount of bleeding in the operation [31]. The blood loss from this procedure is acceptable. Post-perative blood transfusion was no required in this study.

Our technique did not expose outer table of the ilium, so abductor muscle is not injury so that reduce negative Trendelenburg test. We didn't use Kirschner wire so without complication of it.

\subsection{Age at Time Operation}

There always will be children who reach ambulatory age with developmental dysplasia of the hip, either secondary to delayed diagnosis or failed treatment. Once identified, treatment of developmental dysplasia of the hip in this age 
group is based largely on the experience of the surgeon.

Although treatment varies from closure to open reduction with the combination of the femur and pelvis, the goal is largely to obtain a concentric reduction without recurrence of subluxation or dislocation or and without stiffness or avascular necrosis.

Despite the concern that open abduction leads to stiffness and increased necrotizing necrotizing necrosis, the success of open fall in this age group is clear. It provides visual confirmation of the suitability of the reduction while generally making the femoral head not injured. In addition, the OR give the surgeon the opportunity to assess the amount of acetabular dysplasia [36]. In this age, Zionts and MacEwen [37] found that closed reduction was associated with a high rate of $\mathrm{AVN}(23.7 \%)$ and a high incidence of secondary procedures for recurrent subluxation or persistent acetabular dysplasia

They detected that nearly $66 \%$ of patients treated with traction, adductor tenotomy, and closed reduction under general anesthesia required secondary surgical procedures.

Similarly, Mardem-Bey and MacEwen [38] detected that 66\% of children of walking age with developmental dysplasia of the hip who had undergone closed reduction required additional surgery, compared with $33 \%$ of those patients treated with OR. Galpin et al. in a study of 33 hips in 25 patients aged 2 years and older who received one-stage surgery, they reported clinically satisfactory results in $85 \%$ of patients and roentgenographyin $75 \%$ [39]. Ryan et al. [40] detected that treatment outcomes for DDH cases were as follows: excellent results inseven hips; good results in 11, fair results in 4 and poor results in 3 . Eleven hip nocturnal evidence of bone. Nakamura et al. [41] detected: five joints excellent results, three good and three fair. In this study, 37 hips (88\%) had good or excellent clinical and radiological results at the final follow-up. Our patients had $77.3 \%$ hips excellent results; $17.7 \%$ good results, $3.5 \%$ fair results and $1.5 \%$ poor results (Table 5). Radiological results were excellent 79.8\%, good 15.2\%, fair $3.5 \%$, and poor $1.5 \%$ (Table 6 ).

This above age for OR and the remaining potential for acetabular remodeling

Table 5. Barrett Modified McKay criteria for clinical evaluation [24].

\begin{tabular}{|c|c|c|c|c|c|}
\hline & \multirow{2}{*}{ Number hip } & \multicolumn{4}{|c|}{ Modified McKay criteria for clinical evaluation } \\
\hline & & Excellent (\%) & Good (\%) & Fair $(\%)$ & Poor $(\%)$ \\
\hline Variant 1 & 129 & $\begin{array}{c}98 \\
(76.0)\end{array}$ & $\begin{array}{c}24 \\
(18.6)\end{array}$ & $\begin{array}{c}5 \\
(3.9)\end{array}$ & $\begin{array}{c}2 \\
(1.5)\end{array}$ \\
\hline Variant 2 & 69 & $\begin{array}{c}55 \\
(79.8)\end{array}$ & $\begin{array}{c}11 \\
(15.9)\end{array}$ & $\begin{array}{c}2 \\
(2.9)\end{array}$ & $\begin{array}{c}1 \\
(1.4)\end{array}$ \\
\hline Overall & 198 & $\begin{array}{c}153 \\
(77.3)\end{array}$ & $\begin{array}{c}35 \\
(17.7)\end{array}$ & $\begin{array}{c}7 \\
(3.5)\end{array}$ & $\begin{array}{c}3 \\
(1.5)\end{array}$ \\
\hline \multicolumn{2}{|c|}{$\mathrm{P}$ valuate } & 0.540 & 0.832 & 0.960 & 0.578 \\
\hline
\end{tabular}

V 1/V 2 with accepted result 112 hips (86.8\%)/66 hips (95.7\%) and none accepted 7 hips (5.4\%). 
Table 6. Deformity of femoral head or neck or acetabulum according to Severin [22].

\begin{tabular}{|c|c|c|c|c|c|c|c|}
\hline & \multirow[b]{2}{*}{$\begin{array}{c}\text { Number } \\
\text { hip }\end{array}$} & \multicolumn{6}{|c|}{ Severin criteria } \\
\hline & & $\begin{array}{c}\text { Type I } \\
(\%)\end{array}$ & $\begin{array}{c}\text { Type II } \\
(\%)\end{array}$ & $\begin{array}{c}\text { Type } \\
\text { III } \\
(\%)\end{array}$ & $\begin{array}{c}\text { Type IV } \\
(\%)\end{array}$ & $\begin{array}{c}\text { Type V } \\
(\%)\end{array}$ & $\begin{array}{c}\text { Type VI } \\
(\%)\end{array}$ \\
\hline Variant 1 & 129 & $\begin{array}{c}102 \\
(79.1)\end{array}$ & $\begin{array}{c}20 \\
(15.5)\end{array}$ & 0 & $\begin{array}{c}5 \\
(3.9)\end{array}$ & & $\begin{array}{c}2 \\
(1.5)\end{array}$ \\
\hline \multirow[t]{2}{*}{ Variant 2} & 69 & $\begin{array}{c}56 \\
(81.2 \%)\end{array}$ & $\begin{array}{c}10 \\
(14.5)\end{array}$ & 0 & $\begin{array}{c}2 \\
(2.9)\end{array}$ & & $\begin{array}{c}1 \\
(1.4)\end{array}$ \\
\hline & & $\begin{array}{c}158 \\
(79.8)\end{array}$ & $\begin{array}{c}30 \\
(15.2)\end{array}$ & & $\begin{array}{c}7 \\
(3.5)\end{array}$ & & $\begin{array}{c}3 \\
(1.5)\end{array}$ \\
\hline \multicolumn{2}{|c|}{$\mathrm{P}$ valuate } & 0.7270 & 0.8500 & & 0.9609 & & 0.5789 \\
\hline
\end{tabular}

V 1/V 2 with favorable result 122 hips (94.6\%)/66 hips (95.7\%) and none favorable 7 hips (5.4\%)/3 hips 3 (4.3\%). Overall Excellent 79.8\%, Good 15.2\%, Fair 3.5\%, Poor 1.5\%.

are controversial. Ok et al. [42] conclusions that if it is possible to achieve well-functioning hip joints with biological regeneration, OR is a reasonable strategy for untreated dislocation in patients, even those over 8 years of age.

Although many authors believe that the age limit is more than eight years for treatment, they found that repairing the joint continues even after this age after reducing a portion of the developmentally dislocated hip.

We agree Abdullah's opinion [35] that "no relationship between the age at the time of treatment and the final outcome" V1/V2 with favorable result 112 hips $(86.8 \%) / 66$ hips (95.7\%) and unfavorable result 7 hips (5.4\%)/3 hips (4.3\%). Overall favorable result 188 hips (94.9\%) and unfavorable result 10 hips (5.1\%) with $P$ valuate $>0.05$, no Statistical significance (Table 4 ).

Developmental dysplasia of the hip includes femoral head subluxation or dislocation and/or acetabular dysplasia [43]. The treatment of DDH after the walking age group is often surgical because of the pathological changes present in this age [44].

The choice of the type of pelvic osteotomy depends on careful evaluation of the history of the severity of acetabular dysplasia and the age of the patient at the time of treatment [5] [16].

The age restriction for $\mathrm{OR}$ and the potential for acetabular remodeling are controversial. Ok et al. [42] concluded that if there is a good chance of achieving good hip replacement with a biological remodeling, open fracture is a reasonable strategy for untreated dislocation in patients, even on 8 year old.

Although many authors believe that the age limit is more than eight years for treatment, they find that repairing the joint continues even after this age after reducing a portion of DDH. In this study, we did not find a relationship between age younger and older than 18 months at latest Follow-up.

\subsection{Redislocation of the Hip}

Redislocation of the hip Putti [45] distinguished subluxation from dislocation on 
the based of the relationship between the articulation of the thigh and the acetabulum. He noted that the the femoral head in subluxation was positioned abnormally in the socket, while in the dislocation position the head lay completely out from the acetabulum. Although the articular surfaces were in contact, the femoral head was not congruently or concentrically located in the acetabulum. In the current study two patient had resubluxation of the hip (4.5\%). Rudolf et al. [46] reported 3 of 54 hips with redislocation, Grill [47] reported 12 of 50 hips with redislocation and resubluxation.

Ruszkowski and Pucher [48] reported one of 33 hips in 26 children with redislocation. Both Tachdjian [44] and Fixsen [49] suggesting that the reasons for not maintaining a reduced hip are a poorly performed executed osteotomy, a loose capsulorrhaphy, and exessive femoral anteversion.

A precise technique of capsulorhaphy helps to prevent posterior movement of the head femoral during early postoperative period, while the hips are remodelling. Iliac osteotomy in this study with improvement AI so capsulorraphy easily, lax anterior capsular and could prevent posterior dislaction of the hip. In this study, had 14 hips of 198 hips (7.1\%) with redislocation (Table 7).

We suggest that technical failure is often the cause of re-dislocation with all those who have an intact anteromedial capsule, with an inverted transverse ligament, eversion of the limbus, tight psoas tendon, and densing anterior capsule. We perform with all hips was cleared of scar tissue; adductor tenotomy; hips required release of the psoas tendon, eversion of the limbus; release of the transverse ligament was required.

\subsection{Avarcular Necrosis}

Avascular necrosis, femoral head avascular necrosis also called bone infarction, osteonecrosis, ischemic bone necrosis, aseptic necrosis, iscellular death (necrosis) of bone components due to interruption of the blood supply. Without blood, bone tissue would die and bone would collapse

In the etiology of AVN, there are two factors: blockage of the extracapsular

Table 7. Complications.

\begin{tabular}{|c|c|c|c|c|c|c|c|c|c|}
\hline & Redislocation & $\begin{array}{c}\text { Avascular } \\
\text { necrosis (\%) }\end{array}$ & $\begin{array}{c}\text { Coxa } \\
\text { magna }(\%)\end{array}$ & $\begin{array}{c}\text { Coxavara } \\
(\%)\end{array}$ & $\begin{array}{c}\text { Fracture } \\
(\%)\end{array}$ & $\begin{array}{c}\text { Trendelenburg } \\
\text { gait (\%) }\end{array}$ & $\begin{array}{c}\text { Infection } \\
(\%)\end{array}$ & $\begin{array}{c}\text { Limb } \\
\text { Discrepancy } \\
(\%)\end{array}$ & $\begin{array}{c}\text { Sciatic nerve } \\
\text { damage } \\
(\%)\end{array}$ \\
\hline $\begin{array}{c}\mathrm{V} 1 \\
\mathrm{n}=129\end{array}$ & $\begin{array}{c}10 \\
(7.8 \%)\end{array}$ & $\begin{array}{c}33 \\
(25.6)\end{array}$ & $\begin{array}{c}3 \\
(2.3 \%)\end{array}$ & $\begin{array}{c}3 \\
(2.3 \%)\end{array}$ & $\begin{array}{c}2 \\
(1.6 \%)\end{array}$ & $\begin{array}{c}3 \\
(2.3 \%)\end{array}$ & 0 & $\begin{array}{c}10 \\
(7.7)\end{array}$ & 0 \\
\hline $\begin{array}{c}\mathrm{V} 2 \\
\mathrm{n}=69\end{array}$ & $\begin{array}{c}4 \\
(5.8 \%)\end{array}$ & $\begin{array}{c}14 \\
(22.2)\end{array}$ & $\begin{array}{c}1 \\
(1.4 \%)\end{array}$ & $\begin{array}{c}2 \\
(2.8 \%)\end{array}$ & $\begin{array}{c}1 \\
(1.4 \%)\end{array}$ & $\begin{array}{c}5 \\
(8.3 \%)\end{array}$ & 0 & $\begin{array}{c}4 \\
(5.8)\end{array}$ & 0 \\
\hline Overall & $\begin{array}{c}14 \\
(7.1 \%)\end{array}$ & $\begin{array}{c}47 \\
(23.7)\end{array}$ & $\begin{array}{c}4 \\
(2.02)\end{array}$ & $\begin{array}{c}5 \\
(2.5)\end{array}$ & $\begin{array}{c}3 \\
(1.5)\end{array}$ & $\begin{array}{c}5 \\
(2.5)\end{array}$ & 0 & $\begin{array}{c}14 \\
(7.1)\end{array}$ & 0 \\
\hline $\mathrm{P}$ valuate & 0.991 & 0.5477 & & & & 0.09856 & & 0.8255 & \\
\hline
\end{tabular}

Complications: 1) Redislocation: 14 (7.1\%); 2) Avascular necrosis: 47 (23.7); 3) Coxa magna: 4 (2.02\%) 4) Coxavara: 5 (2.52\%); 5) Fracture: 2 (1.01); 6) Trendelenburg gait: 3 (1.5); 7) Sciatic nerve damage: O; 8) Infection: 0 (0\%); 9) Sciatic nerve damage: 0 (\%). 
vessels by immobilization and mechanical pressure. If AVN involves the bones of a joint, it often leads to destruction of the joint articular surfaces. Factore associated with AVN Osteonecrosis is a major complication following surgery for $\mathrm{DDH}$, hindering the subsequent development of the hip. The appearance of early signs of AVN serves as an independent variable. Factors that may be related to the occurrence of AVN include the sex and age of the patient at the time of operation. Unfortunately, AVN the femoral head and physislesions after DDH treatment is a serious complication and prevents long-term positive outcomes [50]. The reported incidence of AVN has ranged from zero to 73 per cent [49]. In addition, the criteria to determine the presence of AVN vary considerably with each series. The most feared complication of treatment for DDH is AVN. In the early stages, it is defined as epiphisytis. After that, vascular damage progresses in femoral proximal areas and in the acetabulum. Kalamchi and MacEwen classify changes in vasculum. Kalamchi reported AVN as between $0 \%$ and 73\% [22]. Barrett had AVN as 6\% [24]. Hajdarhad AVN as 8.1\% [51]. In this study, AVN were 47 of 198 hips (23.7\%) (Table 7).

\section{Other Complications}

\subsection{Lower Limb Discrepancy}

The difference of lower limb discrepancyis both a cosmetic and functional problem. The iliac osteotomy with Fifty-six of 63 hips according to Salter (SIO) had lower limb lengthening, the average of which was $0.47 \mathrm{~cm}$. This may be due to a larger vertical translation of the SIO. No other intervention was performed in patients with a discrepancy of less than $1.5 \mathrm{~cm}$ [52]. In this study, limb length discrepancy was also found in 14 hips (7.1\%) (Table 7) which was less than $3 \mathrm{~cm}$ in all the recorded cases, and needed no further surgical intervention till the latest follow-up.

\subsection{Coxa Magna}

Sakamaki. 1979 [53] repored femoral head enlargement is frequently observed in roentgenography during DDH treatment. By measuring the vertical and horizontal dimensions of both the head and neck of the thigh, they feel that "coxa magna" should be defined as the condition with the expansion of all these parameters. The incidence of coxamagna was $47 \%$ after OR, but only $5 \%$ after closed reduction.

In most cases, coxa magna was roentgenographically evident average 10 months after open reduction. Gamble et al. 1985 [54] studied coxa magna after operative treatment DDH. Coxa magna was show as a femoral head with a horizontal diameter at least $15 \%$ greater than the symmetrical position on the opposite side. Coxa magna developed in 16 hips (33\%). The average increase was $20.9 \%$ (range $15 \%$ - 30\%). There were three factors related with coxa magna: femoral osteotomy (100\%), OR (75\%), and operation at a younger age (mean 15.6 vs. 35.8 months). There were 4 hips (2.2\%) with Coxa magna, 3 hips in patient 
younger than 18 months (V 1), and 1 hip in Patient older than 18 months (V 2). Imatani et al. 1995 [55] reportedcoxa magna after open reduction DDH in 47 hips (47 patients) were radiographically examined for at least 10 years, and another 20 hips (20 patients) were examined arthrographically at an early stage after open reduction. The incidence of coxa magna, defined as a femoral head, is greater than $20 \%$ over the opposite side at the most recent follow-up, at $34.0 \%$, and that appears to be one of the worst factors. Take long-term results.

One of the most important causes of coxa magna is increased widen the acetabular capacity by excising the limbus; Another cause is the invasion of surgery and synovitis of the hip joint after surgery.

\subsection{Supracondylar Femoral Fractures}

Three patients (1.5\%) had complications in this study, they had supracondylar fracture of the femur on the operative side during removal cast three months after the operation. Those fracture was treated by above knee plaster cast. The final clinical outcome was fair in two patients and good in one (Table 7).

Supracondylar and intertrochanteric femoral fractures are rarely observed and during rehabilitation. Long-term fixation exacerbates osteoporosis and increases the risk of fractures. Ege [56] reported the frequency of supracondylar femoral fractures as 1.6\% - 0.8\%; Crellin [57] had 7.6\%; Hajdar [51] had 5.4\%.

\subsection{Trendelenburg Gait}

Trendelenburg gait pattern (or gluteus medius lurch) is an abnormallgait (such as walking) due to weakness of the lower limb muscles, gluteus medius and gluteus minimus. Trendelenburg gait pattern (or gluteus medius lurch) is an abnormallgait (as with walking) caused by weakness of the abductor muscles of the lower limb, gluteus medius and gluteus minimus.

Kershaw et al. 1993 [58] had 21 of 33 hips (63.6\%), Sayed et al. 2012 [59] had 7 of 109 hips (6.4\%), Basant. 2012 [60] had 3 of 35 (8.6\%) with Trendelenburg gait in the final clinical outcome group and are still under follow-up. Our surgical technique with ZOFA did not expose outer table of the illium, abductor muscle injury is limited, so negative Trendelenburg gait. Only 5 hips (2.5\%) with Trendelenburg gait in this study (Table 7).

\section{Conclusions}

Innominate osteotomy combined Fibular allograft was assisted by mechanical stretch and graft was not displaced by both side proximal and distal segment of ilium with a slot receiving fibular allograft and two bar osseous. This operation was of safety and efficacy. Fibular allograft was not resorption, more stable and structurally shown interposition material which could be contoured to the shape of the osteotomy site.

The Zizag octeotomy acetabuloplasty the same shape of the acetabulum by hinging the horizontal branch of the triradiate cartilage following an incomplete 
osteotomy and the aim of this procedure are to improve the anterolateral coverage of the femoral head the same Salter and Pemberton's technique. Immediately operate, AI improvement $27.1^{\circ}$ (53.5\%) with Iliac osteotomy have $135^{\circ}$ angle compared with $\mathrm{AI}<45^{\circ}$ with Iliac osteotomy $90^{\circ}$ angle (Table $4, \mathrm{P}$ valuate 0.02384 , statistical significance). Clinical favorable results were 188 hips (94.9\%) and unfavorable results were 10 hips (5.1\%). Roentgenographic results were Excellent 79.8\%, Good 15.2\%, Fair 3.5\%, Poor 1.5\%. There were redislocation: 14 (7.1\%) and Avascular necrosis: 47 (23.7\%).

The patients were divided into two Variant based on the age at the time of open reduction: 12 months - less than 18 months (Variant 1) and upper 18 - 36 months (Variant 2). At latest results, both Variant were none different.

\section{The Limitation of This Study}

This study comprises its retrospective nature and all the patients were not followed to skeletal maturity. The appearance of remaining hip dysplasia and problems related to subluxation, trochanteric growth and AVN if present should be recognized early and appropriate treatment to ensure optimum results.

\section{References}

[1] Forlin, E., Choi, I.H., Guille, J.T., Bowen, R.J. and Glutting, J. (1992) Prognostic Factors in Congenital Dislocation of the Hip Treated with Closed Reduction: The Importance of Arthrographic Evaluation. The Journal of Bone and Joint Surgery, 74, 1140-1152. https://doi.org/10.2106/00004623-199274080-00003

[2] Noritake, K., Yoshihashi, Y., Hattori, T. and Miura, T. (1993) Acetabular Development after Closed Reduction of Congenital Dislocation of the Hip. The Journal of Bone and Joint Surgery, 75, 737-743. https://doi.org/10.1302/0301-620X.75B5.8376430

[3] Malvitz, T.A. and Weinstein, S.L. (1994) Closed Reduction for Congenital Hip Dysplasia: Functional and Radiographic Results after an Average of Thirty Years. The Journal of Bone and Joint Surgery, 76, 1777-1792. https://doi.org/10.2106/00004623-199412000-00004

[4] Tönnis, D. (1987) Review of the Literature on Open Reduction of the Hip in Congenital Dysplasia and Dislocation of the Hip in Children and Adults, In: Tönnis, D., Ed., Die Angeborene Huftdysplasie und Huftluxationim Kindes-und Erwachsenenalter, Springer, Berlin, Heidelberg, New York, 332-342.

[5] Berkeley, M.E., Dickson, J.H., Cain, T.E., et al. (1984) Surgical Therapy for Congenital Dislocation of the Hip in Patients Who Are Twelve to Thirty-Six Months Old. The Journal of Bone and Joint Surgery, 66, 412-420. https://doi.org/10.2106/00004623-198466030-00014

[6] Salter, R.B. and Dubos, J.P. (1974) The First Fifteen Years' Personal Experience with Innominate Osteotomy in the Treatment of Congenital Dislocation and Subluxation of the Hip. Clinical Orthopaedics, 98, 72-103. https://doi.org/10.1097/00003086-197401000-00009

[7] Waters, P., Kurica, K., Hall, J., et al. (1988) Salter Innominate Osteotomies in Congenital Dislocation of the Hip. Journal of Pediatric Orthopaedics, 8, 650-655.

https://doi.org/10.1097/01241398-198811000-00004 
[8] Smith, B.G., Millis, M.B., Jaramillo, D., Kasser, J.R. and Hey, L.A. (1997) Post Reduction Computed Tomography in Developmental Dislocation of the Hip. Part I, Analysis of Measurement Reliability. Journal of Pediatric Orthopaedics, 17, 626-230. https://doi.org/10.1097/01241398-199709000-00010

[9] El-Sayed, M.M. (2009) Single-Stage Open Reduction, Salter Innominate Osteotomy, and Proximal Femoral Osteotomy for the Management of Developmental Dysplasia of the Hip in Children between the Ages of 2 and 4 Years. Journal of Pediatric Orthopaedics, 18, 188-196. https://doi.org/10.1097/BPB.0b013e32832bf618

[10] Badgley, C.E. (1943) Correlation of Clinical and Anatomical Facts Leading to a Conception of Etiology of Congenital Hip Dysplasias. The Journal of Bone \& Joint Surgery, 25, 503-523.

[11] Georges, M. (1975) The Treatment of Congenital Dislocation and Subluxation of the Hip in the Older Child. Acta Orthopaedica Scandinavica, 46, 364-399.

[12] Gulman, B., Tuncay, I.C., Dabak, N. and Karaismailoglu, N. (1994) Salter's Innominate Osteotomy in the Treatment of Congenital Hip Dislocation: A Long-Term Review. Journal of Pediatric Orthopaedics, 14, 662-666. https://doi.org/10.1097/01241398-199409000-00021

[13] Morin, C., Rabay, G. and Morel, G. (1998) Retrospective Review at Skeletal Maturity of the Factors Affecting the Efficacy of Salter's Innominate Osteotomy in Congenital Dislocated, Subluxed, and Dysplastic Hips. Journal of Pediatric Orthopaedics, 18, 246-253. https://doi.org/10.1097/01241398-199803000-00022

[14] McCluskey, W.P., Bassett, G.S., Mora-Garcia, G. and MacEwen, G.D. (1998) Treatment of Failed Open Reduction for Congenital Dislocation of the Hip. Journal of Pediatric Orthopaedics, 9, 633-639. https://doi.org/10.1097/01241398-198911000-00001

[15] Hsiech, S.M. and Huang, S.C. (1998) Treatment of Developmental Dysplasia of the Hip after Failed Open Reduction. Journal of the Formosan Medical Association, 97, 763-769.

[16] Staheli, L.T. (2006) Developmental Hip Dysplasia. In: Staheli, L.T., Ed., Practice of Pediatric Orthopaedics, Lippincott Williams and Wilkins, Philadelphia, Baltimore, New York, London, Hong Kong, Sydney, Chapter 7, 2nd Edition, 166-181.

[17] Benson, M.K. and Macnicole, M.F. (2002) Developmental Dysplasia of the Hip. In: Benson, M.K., Macnicole, M.F. and Fixsen, J.A., Eds., Children's Orthopaedics and Fractures, Churchill Livingstone, London, Edinburgh, New York, Philadelphia, Toronto, Volume 2, 2nd Edition, 359-381.

[18] Tavares, J.O. and Molinero, K. (2006) Elevation of Medial Tibial Condyle for Severe Tibia Vara. Journal of Pediatric Orthopaedics B, 15, 362-369. https://doi.org/10.1097/01202412-200609000-00011

[19] Kleinberg, S. and Lieberman, H.S. (1936) The Acetabular Index in Infants in Relation to Congenital Dislocation of the Hip. Archives of Surgery, 32, 1049-1054. https://doi.org/10.1001/archsurg.1936.01180240137007

[20] Zadeh, H.G., Catterall, A., Hashemi-Nejad, A. and Perry, R.E. (2000) Test of Stability as an Aid to Decide the Need for Osteotomy in Association with Open Reduction in Developmental Dysplasia of the Hip a Long-Term Review. The Journal of Bone and Joint Surgery, 82, 17-27. https://doi.org/10.1302/0301-620X.82B1.0820017

[21] Tomford, W.W. (1995) Transmission of Disease through Transplantation of Musculoskeletal Allografts. The Journal of Bone \& Joint Surgery, 77, 1742-1754. https://doi.org/10.2106/00004623-199511000-00017

[22] Kalamchi, A. and MacEwen, G.D. (1980) Vascular Necrosis Following Treatment of 
Congenital Dislocation of the Hip. The Journal of Bone \& Joint Surgery, 62, 876-888. https://doi.org/10.2106/00004623-198062060-00002

[23] Severin, E. (1941) Contribution to Knowledge of Congenital Dislocation of Hip Joint: Late Results of Closed Reduction and Arthrographic Studies of Recent Cases. Acta Chirurgica Scandinavica, 84, 1-142.

[24] Barrett, W.P., Staheli, L.T. and Chew, D.E. (1986) The Effectiveness of the Salter Innominate Osteotomy in the Treatment of Congenital Dislocation of the Hip. The Journal of Bone \& Joint Surgery, 68, 79-87. https://doi.org/10.2106/00004623-198668010-00010

[25] Pemberton, P.A. (1965) Pericapsular Osteotomy of the Ilium for Treatment of Congenital Subluxation and Dislocation of the Hip. The Journal of Bone and Joint Surgery, 47, 65-86. https://doi.org/10.2106/00004623-196547010-00004

[26] Salter, R.B. (1961) Innominate Osteotomy in the Treatment of Congenital Dislocation and Suluxation of the Hip. The Journal of Bone and Joint Surgery, 43, 518-539. https://doi.org/10.1302/0301-620X.43B3.518

[27] Tavares, J.O. (2004) Modified Pemberton Acetabuloplasty for the Treatment of Congenital Hip Dysplasia. Journal of Pediatric Orthopaedics, 24, 501-507.

[28] Perlik, P.C., Westin, G.W. and Marafioti, R.L. (1985) A Combination Pelvic Osteotomy for Acetabular Dysplasia in Children. The Journal of Bone and Joint Surgery, 67, 842-850. https://doi.org/10.2106/00004623-198567060-00003

[29] Hung, N.N. (2016) Revision of Outcomes and Complications Following Open Reduction, and Zigzag Osteotomy Combined with Fibular Allograft for Developmental Dysplasia of the Hip in Children. Open Journal of Orthopedics, 6, 184-200. https://doi.org/10.4236/ojo.2016.67026

[30] Lin, C.J., Lin, Y.T. and Lai, K.A. (2000) Intraoperative Instability for Developmental Dysplasia of the Hip in Children 12 to 18 Months of Age as a Guide to Salter Osteotomy. Journal of Pediatric Orthopaedics, 20, 575-578. https://doi.org/10.1097/01241398-200009000-00006

[31] Bohm, P. and Brzuske, A. (2002) Salter Innominate Osteotomy for the Treatment of Developmental Dysplasia of the Hip in Children: Results of Seventy-Three Consecutive Osteotomies after Twenty-Six to Thirty-Five Years of Follow-Up. The Journal of Bone and Joint Surgery, 84, 178-186.

[32] Ito, H., Ooura, H., Kobayashi, M. and Matsuno, T. (2001) Middle-Term Results of Salter Innominate Osteotomy. Clinical Orthopaedics and Related Research, 387, 156-164. https://doi.org/10.1097/00003086-200106000-00021

[33] Harris, N.H., Lloyd-Roberts, G.C. and Gallien, R. (1975) Acetabular Development in Congenital Dislocation of the Hip with Special References to the Indications for Acetabuloplasty and Pelvic or Femoral Realignment Osteotomy. Journal of Bone and Joint Surgery, 57, 46-52. https://doi.org/10.1302/0301-620X.57B1.46

[34] Bos, C.F.A. and Slooff, T.J. (1984) Treatment of Failed Open Reduction for Congenital Dislocation of the Hip. Acta Orthopaedica, 55, 531-535. https://doi.org/10.3109/17453678408992953

[35] Abdullah, et al. (2012) Evaluation of the Results of Operative Treatment of Hip Dysplasia in Children after the Walking Age. Alexandria Journal of Medicine, 48, 115-122. https://doi.org/10.1016/j.ajme.2012.01.002

[36] Ashly, R.K., Larsen, L.J. and James, P.M. (1972) Reduction of Dislocation of the Hip in Older Children. The Journal of Bone and Joint Surgery, 54, 545-550. https://doi.org/10.2106/00004623-197254030-00007 
[37] Zionts, L.E. and MacEwen, G.D. (1986) Treatment of Congenital Dislocation of the Hip in Children between the Ages of One and Three Years. The Journal of Bone and Joint Surgery, 68, 829-846. https://doi.org/10.2106/00004623-198668060-00005

[38] Mardam, T.H. and MacEwen, G.D. (1982) Congenital Hip Dislocation after Walking Age. Journal of Pediatric Orthopaedics, 2, 478-486. https://doi.org/10.1097/01241398-198212000-00003

[39] Galpin, R.D., Road, J.W., Wenger, D.R., Herring, J.A. and Birch, J.G. (1989) One Stage Treatment of Congenital of the Hip in Older Children, Including Femoral Shortening. The Journal of Bone and Joint Surgery, 71, 734-741.

[40] Ryan, M.G., Johnson, L.O., Quanbeck, D.S. and Minkowitz, B. (1998) One-Stage Treatment of Congenital Dislocation of the Hip in Children Three to Ten Years Old: Functional and Radiographic Results. The Journal of Bone and Joint Surgery, 80, 336-344. https://doi.org/10.2106/00004623-199803000-00005

[41] Nakamura, S., Ninomiya, S., Takatori, Y., Morimoto, S. and Umeyama, T. (1998) Long-Term Outcome of Rotational Acetabular Osteotomy: 145 Hips Followed for 10-23 Years. Acta Orthopaedica Scandinavica, 69, 259-265. https://doi.org/10.3109/17453679809000926

[42] Ok, I.Y., Kim, S.J. and Ok, J.H. (2007) Operative Treatment of Developmental Hip Dysplasia in Children Aged over 8 Years. Journal of Pediatric Orthopaedics, 16, 256-261. https://doi.org/10.1097/BPB.0b013e32801088f1

[43] Beaty, H. (1998) Congenital and Developmental Dysplasia of the Hip. In: Canale, T., Ed., Cambells $s$ Operative Orthopaedics, CV Mosby Company, St Louis, Boston, Chicago, London, Toronto, Baltimore, Vol. 2, 9th Edition, 1079-1117.

[44] Tachdjian, M.O. (1972) Deformities of the Lower Limb. In: Tachdjian, M.O., Ed., Pediatric Orthopaedic, W.B. Sunders Company, Philadelphia, London, Toronto, Vol. 1, 129-176.

[45] Putti, V. (1965) Early Treatment of Congenital Dislocation of the Hip. Journal of Bone and Joint Surgery, 47, 602-606. https://doi.org/10.2106/00004623-196547030-00021

[46] Rudolf, G., Christof, R., Gert, P., Hans, M., Gabriele, K. and Grill, F. (2005) Treatment Options for Developmental Dislocation of the Hip after Walking Age. Journal of Pediatric Orthopaedics, 14, 139-150. https://doi.org/10.1097/01202412-200505000-00001

[47] Grill, F. (1984) Treatment of Hip Dislocation after Walking Age. Archives of Orthopaedic and Trauma Surgery, 102, 148-153. https://doi.org/10.1007/BF00575223

[48] Ruszkowski, K. and Pucher, A. (2005) Simultaneous Open Reduction and Degatransiliac Osteotomy for Developmental Dislocation of the Hip in Children under 24 Months of Age. Journal of Pediatric Orthopaedics, 25, 695-701. https://doi.org/10.1097/01.bpo.0000164877.97949.22

[49] Fixsen, J.A. (1987) Anterior and Posterior Subluxation of the Hip Following Innominate Osteotomy. Journal of Bone and Joint Surgery, 69, 361-364. https://doi.org/10.1302/0301-620X.69B3.3584185

[50] Tönnis, D. and Heinecke, A. (1999) Acetabular and Femoral Anteversion: Relationship with Osteoarthritis of the Hip. Journal of Bone and Joint Surgery, 81, 1747-1770. https://doi.org/10.2106/00004623-199912000-00014

[51] Haidar, R.K., Jones, R.S., Vergroesen, D.A. and Evans, G.A. (1996) Simultaneous Open Reduction and Salter Innominate Osteotomy for Developmental Dysplasia of the Hip. Journal of Bone and Joint Surgery, 78, 471-476.

https://doi.org/10.1302/0301-620X.78B3.0780471 
[52] Beaty, J.H. (2007) Congenital Abnormalities of Lower Limb. In: Canale, S.T., Ed., Campbell $s$ Operative Orthopaedics, 10th Edition, Vol. 2, Mosby, St. Louis, 10421069.

[53] Sakamaki, T. (1979) Clinical Study on Coxa Magna during the Treatment in Congenital Dislocation in the Hip. Nihon Seikeigeka Gakkai Zasshi, 53, 491-504.

[54] Gamble, J.G., Mochizuki, C., Bleck, E.E. and Rinsky, L.A. (1985) Coxa Magna Following Surgical Treatment of Congenital Hip Dislocation. Journal of Pediatric Orthopaedics, 5, 528-533. https://doi.org/10.1097/01241398-198509000-00004

[55] Imatani, J., Miyake, Y., Nakatsuka, Y., Akazawa, H. and Mitani, S. (1995) Coxa Magna after Open Reduction for Developmental Dislocation of the Hip. Journal of Pediatric Orthopaedics, 15, 337-341.

https://doi.org/10.1097/01241398-199505000-00015

[56] Ege, R., Bayındır, S., Baki, C., Kutlu, A. and Salter, P. (1994) Innominate Osteotomisi. In: Ege, R., Ed., Kalçacerrahisivesorunları, THK Basımevi, Ankara, 348-388.

[57] Crellin, R.Q. (1974) Innominate Osteotomy for Congenital Dislocation and Subluxation of the Hip: A Follow-Up Study. Clinical Orthopaedics and Related Research, 98, 171-177. https://doi.org/10.1097/00003086-197401000-00019

[58] Kershaw, C.J., Ware, H.E., Pattinson, R. and Fixsen, J.A. (1993) Revision of Failed Open Reduction of Congenital Dislocation of the Hip. Journal of Bone and Joint Surgery, 75, 744-749. https://doi.org/10.1302/0301-620X.75B5.8376431

[59] Sayed, M.E., Ahmed, T., Fathy, S. and Zyton, H. (2012) The Effect of Dega Acetabuloplasty and Salter Innominateosteotomy on Acetabular Remodeling Monitored by the Acetabular Index in Walking DDH Patients between 2 and 6 Years of Age: Short- to Middle-Term Follow-Up. Journal of Children's Orthopaedics, 6, 471-477. https://doi.org/10.1007/s11832-012-0451-x

[60] Basant, K.B. (2012) Outcome of One-Stage Treatment of Developmental Dysplasia of Hip in Older Children. Indian Journal of Orthopaedics, 46, 548-555.

https://doi.org/10.4103/0019-5413.101035 